\title{
Rate of oxidative modification of cytochrome $c$ by hydrogen peroxide is modulated by Hofmeister anions
}

\author{
Nataša Tomášková ${ }^{1}$, Lenka Varinská ${ }^{1,2}$ and Erik Sedlák ${ }^{1}$ \\ ${ }^{1}$ Department of Biochemistry, Institute of Chemistry, Faculty of Science, P. J. Šafárik University, Košice, Slovakia \\ ${ }^{2}$ Department of Pharmacology, Faculty of Medicine, P. J. Šafárik University, Košice, Slovakia
}

\begin{abstract}
Cytochrome $c$ (cyt $c$ ) and other heme proteins are oxidatively modified in the presence of hydrogen peroxide in a concentration- and time-dependent manner. Cyt $c$ modification has been monitored by several spectral probes by absorption spectroscopy (at wavelengths $410 \mathrm{~nm}, 530$ $\mathrm{nm})$, and circular dichroism $(222,268,288$ and $417 \mathrm{~nm})$. Kinetics monitored with these spectral probes indicates that the oxidative modification of cyt $c:$ i) proceeds in the order: heme $\rightarrow$ aromatic amino acids $\rightarrow$ secondary structure, and ii) the rate of the oxidative modification is proportional to the protein flexibility. The flexibility of cyt $c$ was modulated by anions of Hofmeister series (sulfate, chloride, perchlorate) (Varhač et al. 2009). A minimalist scheme of the interaction of cyt $c$ with hydrogen peroxide can be described by two steps: 1) interaction of hydrogen peroxide with heme iron forming the postulated ferryl intermediate, 2a) oxidation of another molecule of hydrogen peroxide and $2 \mathrm{~b}$ ) parallel oxidation of close amino acid residue(s) and/or heme. The catalase activity of cyt $c$ is independent from the presence of Hofmeister anions, which indicates that both steps ( 1 and 2a) in the catalase reaction are independent from the flexibility of the heme region of the protein matrix. On the other hand, the flexibility of the polypeptide chain of the protein modulates the rate of parallel oxidative modification of the heme and amino acid residues.
\end{abstract}

Key words: Protein flexibility - Protein dynamics - Protein stability - Oxidative damage - Heme proteins

\section{Introduction}

Cytochrome $c$ (cyt $c$ ), a globular protein which contains a heme prosthetic group, is a typical example of multifunctional protein with two important physiological roles: i) to mediate electron shuttling between ubiquinol-cytochrome $c$ oxidoreductase (complex III) and cytochrome $c$ oxidase (complex IV) during mitochondrial respiration, and ii) to serve as a factor regulating preapoptotic events (Liu et al. 1996; Acehan et al. 2002). Moreover, this cyt $c$ is able to catalyze peroxidase-like reactions in the presence of an electron acceptor, such as hydrogen peroxide or an organic hydroperoxide (Radi et al. 1991; Vazquez-Duhalt 1999; Kagan et al. 2005). In addition, cyt $c$ is known to alter both the generation and elimination of hydrogen peroxide (Deterding

Correspondence to: Erik Sedlák, Department of Biochemistry, Institute of Chemistry, Faculty of Science, P. J. Šafárik University, Košice, Slovakia

E-mail: erik.sedlak@upjs.sk et al. 1998; Zhao et al. 2003), and to regenerate dioxygen from superoxide radical anion (Pereverzev et al. 2003). In classical peroxidase reaction the oxidation of substrates generally proceeds through two oxo-ferryl intermediates, called Compound I and Compound II, which are two and one oxidizing equivalents, respectively, above the Fe(III) state (Dawson 1988). Hemoglobin (Smith and Beck 1967), myoglobin (Kelman et al. 1994), cyt c (Vazquez-Duhalt 1999), heme peptide microperoxidase (Casella et al. 2000) and heme $c$ (Shedbalkar et al. 1988) show peroxidase-like activity similar to classical peroxidases, though their reactivities with hydrogen peroxide are quite different. Although cyt $c$ is a sluggish catalase/peroxidase, it can be physiologically relevant due to its high in vivo concentration (Belikova et al. 2006).

Cyt $c$ is located in the intermembrane mitochondrial space, where it is exposed to hydrogen peroxide released by mitochondria. All heme proteins including peroxidases are sensitive to oxidation by hydrogen peroxide. The oxidative inactivation of heme proteins seems to be mechanism- 
based, where the protein itself is used as an electron source. The initial radical generation occurs at the heme moiety and gives rise to the formation of protein radicals (Valderrama et al. 2002). These species are believed to be formed by an initial two-electron oxidation of iron(III)porphyrin giving rise to Compound I, which consists of a high-valence, oxoiron(IV)porphyrin-based, $\pi$-free, radical cation. In some cases, the second oxidation equivalent in Compound I is delocalized into the protein (Hiner et al. 2001; Pogni et al. 2005). Compound I is reduced to Compound II by a substrate-derived electron, and to the resting ferric state by a second electron (Arnao et al. 1990; Valderrama et al. 2006). Abundant evidence suggests that in the absence of an exogenous electron donor, protein elements such as amino acid residues or the porphyrin moiety itself might perform as potential electron sources (Valderrama et al. 2002; Valderrama and Vazquez-Duhalt 2005), while in the presence of excess hydrogen peroxide Compound III is formed (Arnao et al. 1990). Based on its redox potential, Compound I is a highly-active oxidant that can oxidize close amino acids residues with low redox potentials such as tyrosine, cysteine, tryptophan, and methionine (Prutz 1990; Hawkins and Davies 2001; Lawrence et al. 2003). In vitro oxidation of globular proteins revealed that once a proteinbased, free radical is formed, the fate of free radicals will follow the redox properties of the amino acid side chains, and it is expected that they will eventually converge to the lowest redox potential site available (Prutz 1990; Hawkins and Davies 2001). We suggest that the transfer of radicals depends on dynamics/flexibility of the protein matrix, as dynamics-induced exposure of amino acids to solvent may affect both the redox properties of amino acids as well as the route of radicals through the polypeptide chain. It has been shown that an increased exposure of the hydrophobic core due to misfolding accompanied with increased protein dynamics/flexibility lead to an increased oxidative modification of proteins (Dukan et al. 2000). This indicates that increased dynamics/flexibility of protein structures might play an important role in the rate and/or extent of oxidative modifications of proteins.

It is generally accepted that stability and conformational dynamics/flexibility are inversely related to each other (Vihinen 1987; Tang and Dill 1998; Tsai et al. 2001). Although the terms "dynamics" and "flexibility" in complex systems are usually interchangeable, they in fact describe different properties. "Dynamics" describes motion(s) with a certain time scale, while "flexibility" has no particular time reference but implies multiple structures that are of comparable energy and can be interconverted with a series of small changes (Richards 1992). Apparently, their interchangeable use follows from the fact that decreasing a barrier between two states increases rate of interconversion (dynamics) as well as accessibility of these two states (flexibility).
Cyt $c$ in the intermembrane space consists of two populations: i) free cyt $c$, and ii) cyt $c$ bound to the inner mitochondrial membrane. Cyt $c$ in complex with negativelycharged membrane surface is destabilized with high dynamics/flexibility of its protein matrix (Pinheiro 1994; Pinheiro et al. 2000). Recently, we showed that protein flexibility, monitored by binding of a small ligand hydrogen cyanide, into the heme of cyt $c$ depends on the presence of anions and their position in Hofmeister series (Varhač et al. 2009). We hypothesized that hydrogen peroxide, a comparably small ligand, "feels" the same flexibility effects. Therefore, to address how flexibility of the protein matrix affects its modification by hydrogen peroxide, we used the Hofmeister anions: kosmotropic sodium sulfate, neutral (from the Hofmeister point of view) sodium chloride and chaotropic sodium perchlorate.

In the present study, we have analyzed time-order of oxidative modification of different parts of the cyt $c$ structure by hydrogen peroxide. We show that the oxidative modification of cyt $c$ proceeds in the order: heme $\rightarrow$ aromatic amino acids $\rightarrow$ secondary structure, and the rate of the oxidative modification is proportional to protein flexibility. Our results indicate that the oxidative modification of the polypeptide chain is not related to the catalase activity of cyt $c$ but it depends on flexibility of its polypeptide chain.

\section{Materials and Methods}

Horse heart cyt $c$, type VI, was obtained from Sigma and used without further purification. The concentration of oxidized cyt $c$ was determined spectrophotometrically at $410 \mathrm{~nm}\left(\varepsilon=106100 \mathrm{l} \cdot \mathrm{mol}^{-1} \cdot \mathrm{cm}^{-1}\right)$ at $\mathrm{pH} 7.0 \mathrm{in} 10 \mathrm{mmol} \cdot \mathrm{l}^{-1}$ sodium phosphate buffer. The hydrogen peroxide concentration was determined spectrophotometrically at $240 \mathrm{~nm}$

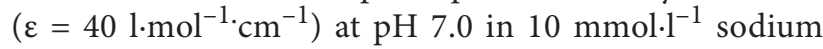
phosphate buffer.

Butylated hydroxytoluene, xylenol orange, sodium sulfate, sodium chloride, sodium perchlorate and hydrogen peroxide were purchased from Sigma. Potassium ferricyanide was purchased from Fluka. Stock solutions of the salts were filtered before use. All buffer components, solvents and other chemical reagents were of analytical grade.

\section{Absorbance spectroscopy}

The spectrophotometric measurements were done on a Varian Cary Bio 100 spectrophotometer equipped with a Peltier element. Difference absorption spectra of time-dependent oxidative modification of cyt $c$ with different concentrations of the hydrogen peroxide from $320-500 \mathrm{~nm}$ (Soret region) and 500-800 $\mathrm{nm}$ were recorded. The spectra were collected in solutions of $10 \mu \mathrm{mol} \cdot \mathrm{l}^{-1}$ and $100 \mu \mathrm{mol} \cdot \mathrm{l}^{-1}$ cyt $c$, respec- 
tively, $10 \mathrm{mmol} \cdot \mathrm{l}^{-1}$ sodium phosphate buffer, and different concentrations of the hydrogen peroxide $\left(0.5-15 \mathrm{mmol} \cdot \mathrm{l}^{-1}\right)$. Absorbance spectra are shown as a dependence of extinction coefficient $(\varepsilon)$ on wavelength, where the extinction coefficient is defined according to the Beer-Lambert law. Potassium ferricyanide, used for oxidation of cyt $c$, was removed from the solution by passage down a Sephadex PD10 column. Control measurements performed in the presence of $1 \mu \mathrm{mol} \cdot \mathrm{l}^{-1}$ of potassium ferricyanide show that the ferricyanide does not affect kinetics of oxidative modification of cyt $c$ by hydrogen peroxide (data not shown). The spectra were collected every $150 \mathrm{~s}$ over $30 \mathrm{~min}$. All measurements were performed at $24.0 \pm 0.2^{\circ} \mathrm{C}$.

\section{Circular dichroism measurements}

The circular dichroism (CD) measurements were carried out on a Jasco J-810 spectropolarimeter (Japan). Time dependent CD spectra were collected in a solution of $8 \mu \mathrm{mol} \cdot \mathrm{l}^{-1}$ or $30 \mu \mathrm{mol} \cdot \mathrm{l}^{-1}$ cyt $c, 10 \mathrm{mmol} \cdot \mathrm{l}^{-1}$ sodium phosphate buffer, $1 \mu \mathrm{mol} \cdot \mathrm{l}^{-1}$ potassium ferricyanide and different concentrations of the hydrogen peroxide $\left(0.5-15 \mathrm{mmol} \cdot \mathrm{l}^{-1}\right)$. CD spectra were recorded from 450 to $350 \mathrm{~nm}$ and from 350 to $250 \mathrm{~nm}$ in $1 \mathrm{~cm}$ path length quartz cell cuvettes and from 250 to $190 \mathrm{~nm}$ in $0.1 \mathrm{~cm}$ path length quartz cell cuvettes with resolution of $0.1 \mathrm{~nm}$, scan speed of $50 \mathrm{~nm} \cdot \mathrm{min}^{-1}$, time constant $1.0 \mathrm{~s}, 1.0 \mathrm{~nm}$ band width and standard sensitivity. CD spectra are shown as a dependence of mean residue ellipticity $(\Theta)$ as defined in the work of Kelly et al. (2005). All experiments were carried out under nitrogen atmosphere and room temperature.

\section{Kinetics studies}

Kinetic measurements were performed with a Varian Cary Bio 100 spectrophotometer equipped with a Peltier element and with a Jasco J-810 spectropolarimeter. The kinetics of oxidative modification was measured in $10 \mathrm{mmol} \cdot \mathrm{l}^{-1} \mathrm{so}$ dium phosphate buffer, $\mathrm{pH} 7.0$, in the presence and in the absence of $1 \mathrm{~mol} \cdot \mathrm{l}^{-1}$ salts $\left(\mathrm{NaCl}, \mathrm{Na}_{2} \mathrm{SO}_{4}\right.$ and $\left.\mathrm{NaClO}_{4}\right)$ at $24.0 \pm 0.5^{\circ} \mathrm{C}$.

The oxidative modification of cyt $c$ was followed at 410 , 530, 417, 288, 268 and $222 \mathrm{~nm}$. The absorbance data were fitted as a function of time to a double exponential function of the form:

$$
A_{\mathrm{t}}=A_{1} \exp \left(-k_{1} t\right)+A_{2} \exp \left(-k_{2} t\right)
$$

where $A_{\mathrm{t}}$ is the absorbance at time $t, A_{1}$ and $A_{2}$ are sums of the total change in absorbance between $t=0$ and $t=\infty, k_{1}$ and $k_{2}$ are the observed pseudo first-order rate constants for two phases of oxidation reaction.

The second-order (bimolecular) rate constant (association rate constant, $k_{\mathrm{a}}$ ) was estimated from the slope of the best-fit plot of the pseudo first-order (mono-nuclear) rate constants $k_{\text {obs }}$ against the concentration of hydrogen peroxide according to the following equation:

$$
k_{\text {obs }}=k_{\mathrm{d}}+k_{\mathrm{a}} \cdot\left[\mathrm{H}_{2} \mathrm{O}_{2}\right]
$$

where $k_{\mathrm{d}}$ represents the dissociation rate constant of the cyt $c-\mathrm{H}_{2} \mathrm{O}_{2}$ complex.

\section{Measurement of catalase activity of cyt $c$}

Catalase activity of cyt $c$ was determined by a modified ferrous oxidation-xylenol orange (FOX2) assay (Gay et al. 1999; DeLong et al. 2002). The reaction solution contained $500 \mu \mathrm{mol} \cdot \mathrm{l}^{-1}$ hydrogen peroxide and $500 \mu \mathrm{mol} \cdot \mathrm{l}^{-1}$ cyt $c$ in $10 \mathrm{mmol} \cdot \mathrm{l}^{-1}$ sodium phosphate, $\mathrm{pH} 7.0$, in the presence and in the absence of $1 \mathrm{~mol} \cdot \mathrm{l}^{-1} \mathrm{NaCl}$ or $\mathrm{NaClO}_{4}$. The reaction was initiated by the addition of hydrogen peroxide in final concentration $500 \mu \mathrm{mol} \cdot \mathrm{l}^{-1}$. The concentration of hydrogen peroxide was determined every $5 \mathrm{~min}$ throughout a 30 min reaction in an aliquot of the reaction mixture. The mixture was obtained by centrifugation using Microcon, Ultracel YM-3, with molecular weight cut-off of $3000 \mathrm{Da}$. The aliquot/FOX2 reagent $1 / 9(\mathrm{v} / \mathrm{v})$ mixture was incubated for $30 \mathrm{~min}$ at room temperature. The concentration of hydrogen peroxide was determined using a calibration curve of absorbance at $560 \mathrm{~nm}$ versus hydrogen peroxide in the presence of FOX 2 reagent. The absorbance measurements were performed by a Milton Roy diode-array spectrophotometer.

\section{Results}

\section{Spectral measurements}

Absorption and CD spectra of horse heart cyt $c$ are particularly rich in details over the entire spectral region, reflecting the contributions from various chromophores. Since the origins of most of these transitions are well characterized, the investigations of their changes may aid in interpretations of changes of cyt $c$ induced by hydrogen peroxide.

\section{Changes in absorption spectra during reaction between cyt $c$ and hydrogen peroxide}

Figure 1 shows spectral changes in both Soret and visible regions observed during the reaction of cyt $c$ in the presence of 1 and $10 \mathrm{mmol} \cdot \mathrm{l}^{-1}$ hydrogen peroxide. Intensity and position of the Soret and visible (500-800 nm) bands indicate alterations in the oxidation, spin and coordination states of heme iron and the heme environment. At a lower concentration ( $\left.1 \mathrm{mmol} \cdot \mathrm{l}^{-1}\right)$ of hydrogen peroxide, the isosbestic points observed at 500-600 nm indicate a one-step transition. The state of cyt $c$ at $30 \mathrm{~min}$ is characterized by $\sim 25 \%$ lower extinction of the Soret band with perturbed 


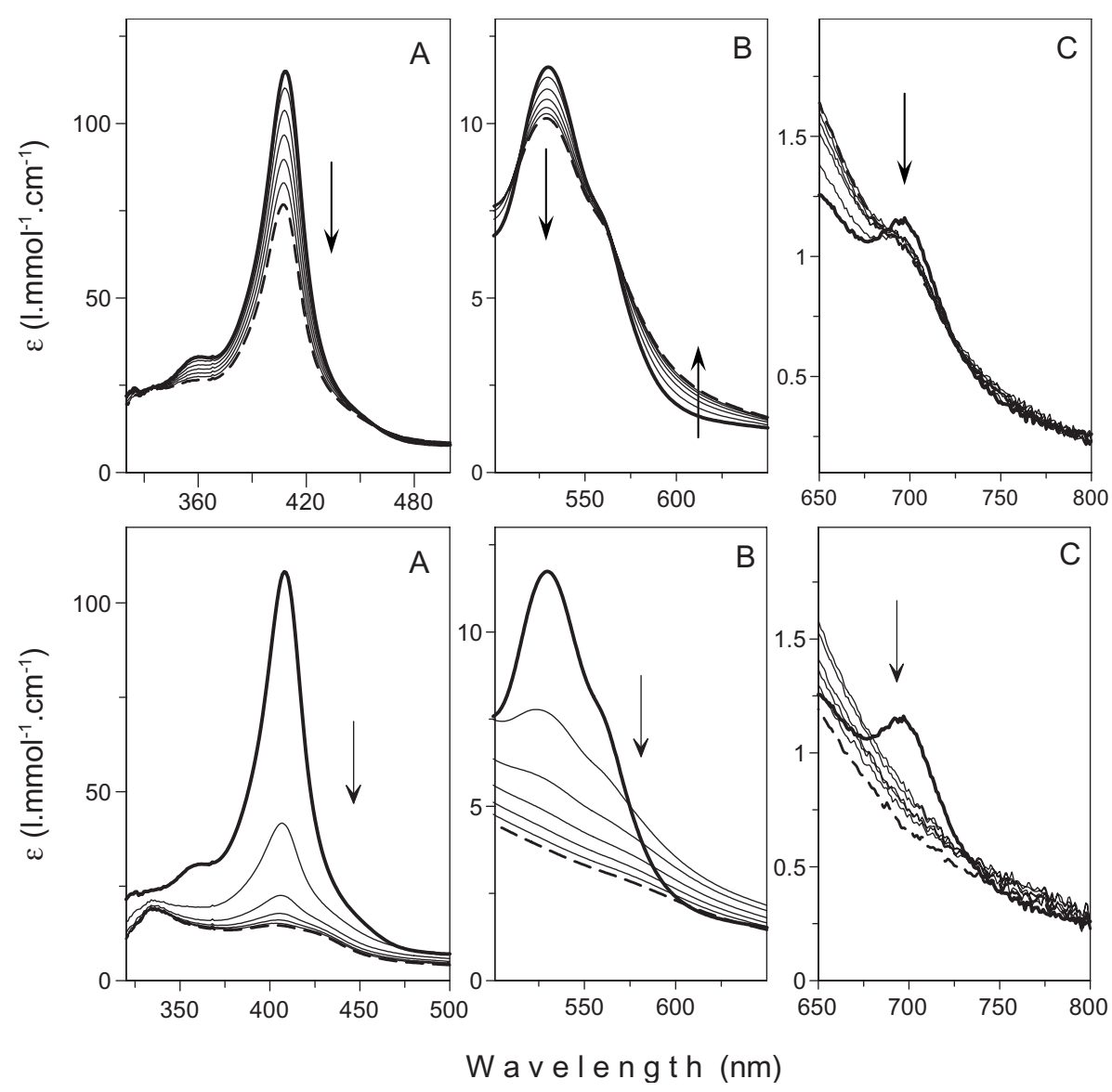

Figure 1. The absorbance spectra of the time-dependent oxidative modification of cyt $c$ induced by hydrogen peroxide at 320-500 nm region (A), 500-650 $\mathrm{nm}$ region (B) and 650-800 nm region $(\mathrm{C})$. The spectra were measured in $10 \mathrm{mmol} \cdot \mathrm{l}^{-1}$ sodium phosphate, $\mathrm{pH} 7.0$ in the presence of $1 \mathrm{mmol} \cdot \mathrm{l}^{-1}$ (upper row) and $10 \mathrm{mmol} \cdot \mathrm{l}^{-1}$ (lower row) hydrogen peroxide. Concentrations of cyt $c$ were $10 \mu \mathrm{mol} \cdot \mathrm{l}^{-1}$ (A) and $100 \mu \mathrm{mol} \cdot \mathrm{l}^{-1}(\mathrm{~B}, \mathrm{C})$. Spectra were collected every $5 \mathrm{~min}$ over a 30 minute period. The arrows indicate the time course of the spectral changes. The spectrum at time 0 minutes is shown as a thick line, the final spectrum (at 30 minutes) is shown as a dashed line. $\varepsilon$, extinction coefficient.

bands at 530 and $695 \mathrm{~nm}$ (Fig. 1, upper row). At a higher concentration $\left(10 \mathrm{mmol} \cdot \mathrm{l}^{-1}\right)$ of hydrogen peroxide, the heme prosthetic group is significantly degraded, as indicated by the diminished absorbance in the Soret region (Fig. 1, lower row). Moreover, the $695 \mathrm{~nm}$ band disappears with time as a result of interaction with hydrogen peroxide, indicating the cleavage of the charge-transfer bond between iron heme and sulfur of Met80 in cyt $c$. The isosbestic points are not observed in the time-dependent spectra of cyt $c$ at high hydrogen peroxide concentrations (Fig. 1, lower row).

\section{Effect of hydrogen peroxide on CD spectra of cyt $c$}

Hydrogen peroxide-induced changes in a CD spectrum of cyt $c$ support and complement findings observed in absorption spectra (Fig. 2). At low $\left(\leq 1 \mathrm{mmol} \cdot \mathrm{l}^{-1}\right)$ hydrogen peroxide concentrations (data not shown) or at early stages of hydrogen peroxide reaction with cyt $c$ at higher concentrations $\left(>2 \mathrm{mmol} \cdot \mathrm{l}^{-1}\right)$, the negative CD signal at $417 \mathrm{~nm}$ in the Soret region disappears while the positive Cotton effect is still present (Fig. 2C). This strongly indicates a perturbation/modification of an interaction between aromatic amino acids, particularly the Phe 82 residue and/or its close environment (Pielak et al. 1986). Both Cotton effects in the Soret spectrum of cyt $c$ are abolished at high $\left(>2 \mathrm{mmol} \cdot \mathrm{l}^{-1}\right)$ concentrations of hydrogen peroxide. This, in accordance with observed changes in absorption spectra (Fig. 1A), can be attributed to degradation of the heme prosthetic group as well as changes of the overall structure of the heme crevice of protein. Analogously, the bands of cyt $c$ at $268 \mathrm{~nm}$ and $288 \mathrm{~nm}$, associated with tryptophan (Myer 1968) and/or tyrosines (Strickland 1974), diminished due to prolonged incubation with the high $\left(>2 \mathrm{mmol} \cdot \mathrm{l}^{-1}\right)$ hydrogen peroxide concentrations (Fig. 2B). Interestingly, the effect of the high 


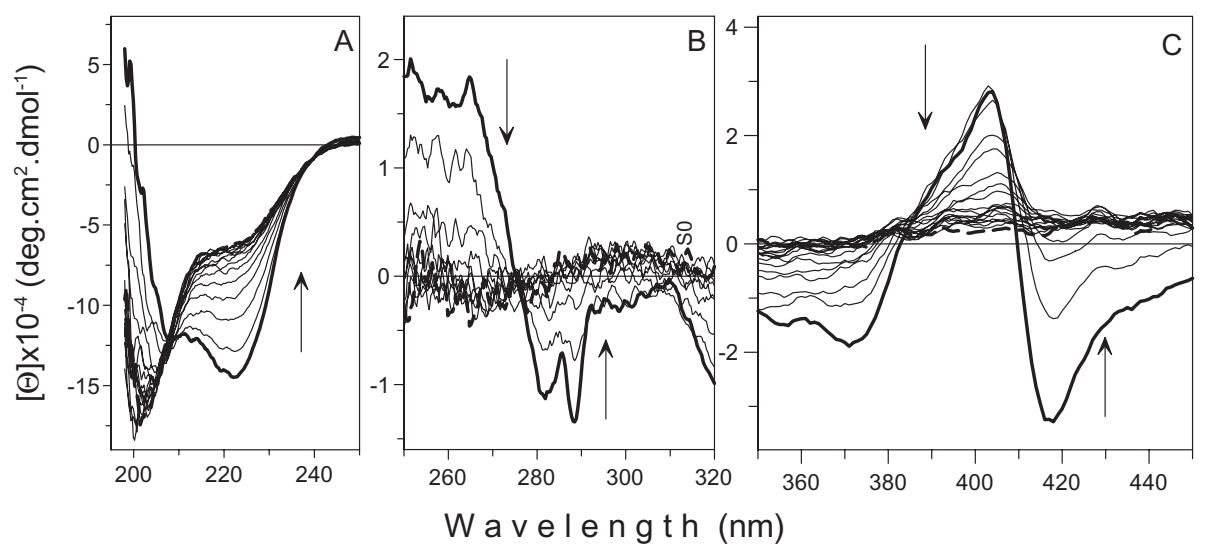

Figure 2. The circular dichroism (CD) spectra of the time-dependent oxidative modification of cyt $c$ by hydrogen peroxide in the farUV (A), near-UV (B) and Soret (C) regions. The CD spectra were measured in $10 \mathrm{mmol} \cdot \mathrm{l}^{-1}$ sodium phosphate, $\mathrm{pH} 7.0$ in the presence of $10 \mathrm{mmol} \cdot \mathrm{l}^{-1}$ hydrogen peroxide. Concentrations of cyt $c$ were $30 \mu \mathrm{mol} \cdot \mathrm{l}^{-1}(\mathrm{~A}, \mathrm{~B})$ and $8 \mu \mathrm{mol} \cdot \mathrm{l}^{-1}(\mathrm{C})$. Spectra were collected every $3 \mathrm{~min}$ over a 30 minute period. The arrows indicate the time course of the spectral changes. The spectrum at time 0 min is shown as a thick line, the final spectrum (at $30 \mathrm{~min}$ ) is shown as a dashed line. $\Theta$, mean residue ellipticity.

concentrations of hydrogen peroxide was also observed in the far-UV region, indicating a perturbation of the secondary structure of cyt $c$ (Fig. 2A). At low $\left(\leq 1 \mathrm{mmol} \cdot \mathrm{l}^{-1}\right)$ hydrogen

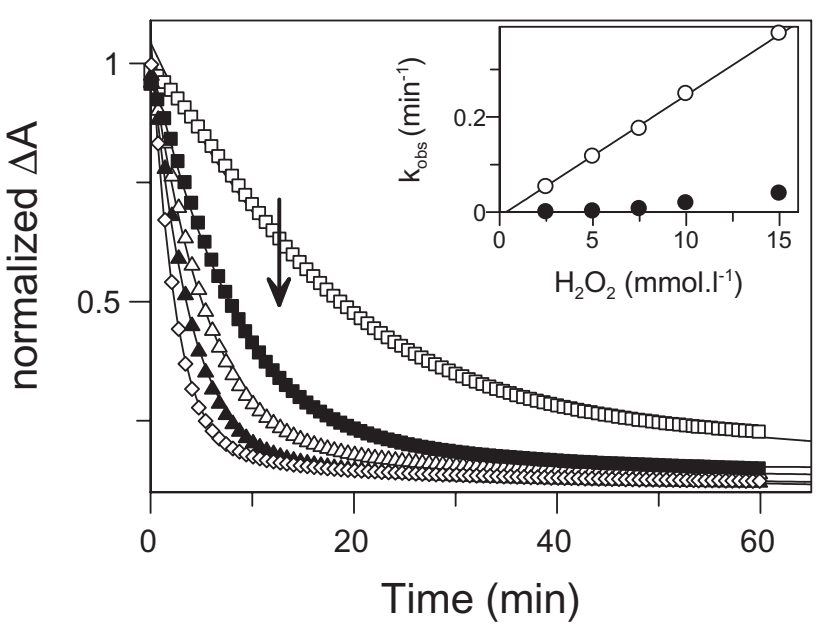

Figure 3. The time course of the absorbance changes at $410 \mathrm{~nm}$ of cyt $c$ induced by addition of hydrogen peroxide $\left(2 \mathrm{mmol} \cdot \mathrm{l}^{-1}\right.$ - white squares, $5 \mathrm{mmol} \cdot \mathrm{l}^{-1}$ - black squares, $7.5 \mathrm{mmol} \cdot \mathrm{l}^{-1}$ - white triangles, $10 \mathrm{mmol} \cdot \mathrm{l}^{-1}$ - black triangles, and $15 \mathrm{mmol} \cdot \mathrm{l}^{-1}$ - white diamonds) to the reaction mixture. The absorbance changes $(\Delta \mathrm{A})$ were normalized to the values of absorbance at 0 minutes. Cyt $c\left(10 \mu \mathrm{mol} \cdot \mathrm{l}^{-1}\right)$ was dissolved in $10 \mathrm{mmol} \cdot \mathrm{l}^{-1}$ sodium phosphate buffer, $\mathrm{pH}$ 7.0, at $24^{\circ} \mathrm{C}$. The arrow indicates dependence of the time courses of the absorbance changes on increasing concentration of hydrogen peroxide. Inset: Dependence of the observed pseudo-first-order rate constants $k_{o b s}$ for fast (white circle) and slow (black circle) phases of the oxidative modification of cyt $c$ on hydrogen peroxide concentration. peroxide concentrations the spectrum of cyt $c$ in the far-UV $\mathrm{CD}$ was unperturbed even after prolonged incubation (data not shown).

\section{Kinetics measurements}

Kinetics of the reaction of hydrogen peroxide with cyt $c$

Kinetics of the effect of hydrogen peroxide on cyt $c$ were measured over a concentration range $2-15 \mathrm{mmol} \cdot \mathrm{l}^{-1}$ of hydrogen peroxide. Figure 3 shows typical kinetic traces of the change of absorbance at $410 \mathrm{~nm}$ of cyt $c$ due to its reaction with different concentrations of hydrogen peroxide. The change in absorbance at $410 \mathrm{~nm}$ with respect to time is well described by a double exponential function containing: i) fast phase with $\sim 85 \%$ of the amplitude and ii) slow phase with a nonlinearly increasing rate constant (at $15 \mathrm{mmol} \cdot \mathrm{l}^{-1}$ hydrogen peroxide, the slow phase is $\sim 10$-times slower than the fast phase) with $\sim 15 \%$ amplitude. The observed pseudofirst-rate constants of the faster phase, $k_{o b s}$, are linearly dependent on the concentration of hydrogen peroxide (Fig. 3, inset). The association rate constants of the reaction, $k_{\mathrm{a}}$, were calculated from slopes of these linear plots according to the Equation 2 (Table 1).

To monitor the oxidative modification of different parts of the protein structure, kinetics measurements were performed at several different wavelengths: 410 and $530 \mathrm{~nm}$ by absorbance spectroscopy and at 222, 268, 288 and $417 \mathrm{~nm}$ by CD. Second-order rate constants (Fig. 4) show the fastest change in the ellipticity at $417 \mathrm{~nm}\left(k_{\mathrm{a}}=\right.$ $\left.0.841 \cdot \mathrm{mol}^{-1} \cdot \mathrm{s}^{-1}\right)$ that monitors overall changes in the heme crevice, particularly, heme/aromatic amino acids interac- 
Table 1. The second-order rate constants of oxidative modification of cyt $c$ followed by absorbance spectroscopy (Abs) at $410 \mathrm{~nm}, 530$ $\mathrm{nm}$, and by circular dichroism (CD) at $417 \mathrm{~nm}, 268 \mathrm{~nm}, 288 \mathrm{~nm}$ and $222 \mathrm{~nm}$ in the presence of $1 \mathrm{~mol}^{-1} \mathrm{Na}_{2} \mathrm{SO}_{4}, \mathrm{NaCl}_{\text {and NaClO}}$ and without salt in $10 \mathrm{mmol} \cdot \mathrm{l}^{-1}$ sodium phosphate buffer $\left(\mathrm{pH} 7.0,24^{\circ} \mathrm{C}\right)$

\begin{tabular}{cccccc}
\hline \multirow{2}{*}{ Method } & $\begin{array}{c}\text { Wavelength } \\
(\mathrm{nm})\end{array}$ & buffer & $\mathrm{Na}_{2} \mathrm{SO}_{4}$ & $\mathrm{NaCl}$ & $\mathrm{NaClO}_{4}$ \\
\cline { 3 - 5 } & 410 & $0.43 \pm 0.01$ & $0.50 \pm 0.02$ & $0.43 \pm 0.02$ & $0.84 \pm 0.03$ \\
\multirow{2}{*}{$\mathrm{Abs}$} & 530 & $0.33 \pm 0.02$ & $0.34 \pm 0.02$ & $0.39 \pm 0.02$ & $0.77 \pm 0.02$ \\
\cline { 2 - 5 } & 417 & $0.84 \pm 0.01$ & $0.62 \pm 0.01$ & $0.82 \pm 0.01$ & $2.82 \pm 0.10$ \\
& 288 & $0.37 \pm 0.01$ & $0.30 \pm 0.01$ & $0.57 \pm 0.01$ & $1.60 \pm 0.10$ \\
$\mathrm{CD}$ & 268 & $0.41 \pm 0.01$ & $0.45 \pm 0.01$ & $0.56 \pm 0.01$ & $1.20 \pm 0.02$ \\
& 222 & $0.26 \pm 0.01$ & $0.19 \pm 0.01$ & $0.35 \pm 0.01$ & $0.81 \pm 0.02$ \\
\hline
\end{tabular}

The listed errors correspond to uncertanities in the obtained fitting parameters.

tion. The heme region modification is followed by changes in the aromatic amino acids region with $k_{\mathrm{a}} \sim 0.4 \mathrm{l} \cdot \mathrm{mol}^{-1} \cdot \mathrm{s}^{-1}$. The slowest changes were observed in secondary structure of the protein monitored by ellipticity at $222 \mathrm{~nm}\left(k_{\mathrm{a}}=\right.$ $\left.0.261 \cdot \mathrm{mol}^{-1} \cdot \mathrm{s}^{-1}\right)$.

Effect of flexibility of cyt $c$ on its oxidative modification by hydrogen peroxide

Recently, we showed that the protein flexibility can be modulated by anions of Hofmeister series (Varhač et al. 2009). In

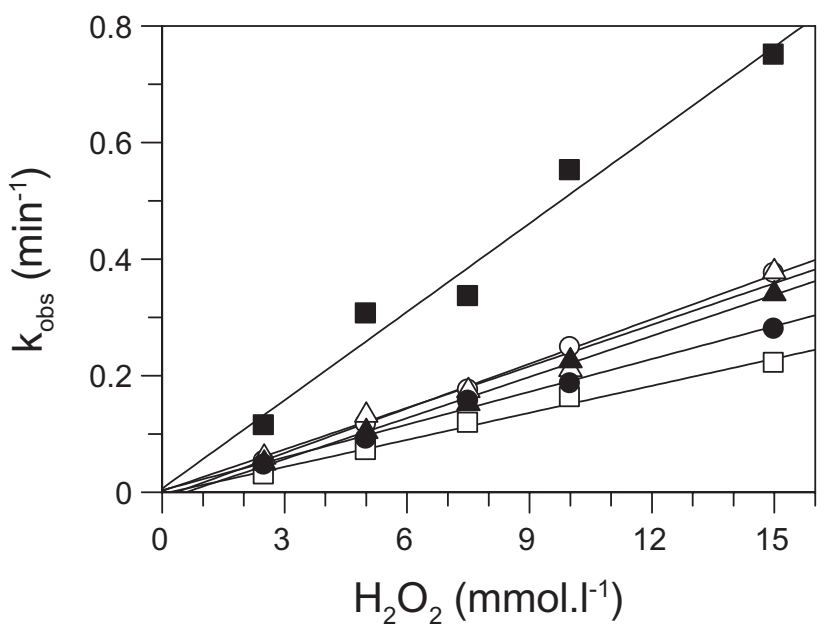

Figure 4. Dependence of the apparent rate constant $\left(k_{o b s}\right)$ on the oxidative modification of cyt $c$ by hydrogen peroxide measured at different wavelengths: $410 \mathrm{~nm}$ (white circles), $530 \mathrm{~nm}$ (black circles) - by absorbance spectroscopy, and $417 \mathrm{~nm}$ (black squares), $288 \mathrm{~nm}$ (black triangles), $268 \mathrm{~nm}$ (white triangles) and $222 \mathrm{~nm}$ (white squares) - by CD method. Kinetics were measured in $10 \mathrm{mmol} \cdot \mathrm{l}^{-1}$ sodium phosphate buffer, $\mathrm{pH} 7.0$ at $24^{\circ} \mathrm{C}$ in the presence of different concentration of hydrogen peroxide $\left(0.5-15 \mathrm{mmol} \cdot \mathrm{l}^{-1}\right)$. accordance with our previous findings, in the present work we found that the bimolecular rate constants of the oxidative modification of cyt $c$ depend on the position of anions in Hofmeister series (Fig. 5, Table 1). Moreover, Figure 5 shows that the rate constants at all wavelengths (except at $410 \mathrm{~nm}$ of absorption spectrum, see Discussion) have the same tendency: they increase in dependence on their positions in the Hofmeister series in the order sulfate $<$ chloride $<$ perchlorate, i.e. from kosmotropic to chaotropic anions. This indicates a correlation between the oxidative modification of cyt $c$ and the flexibility of its protein matrix (Varhač et al. 2009).

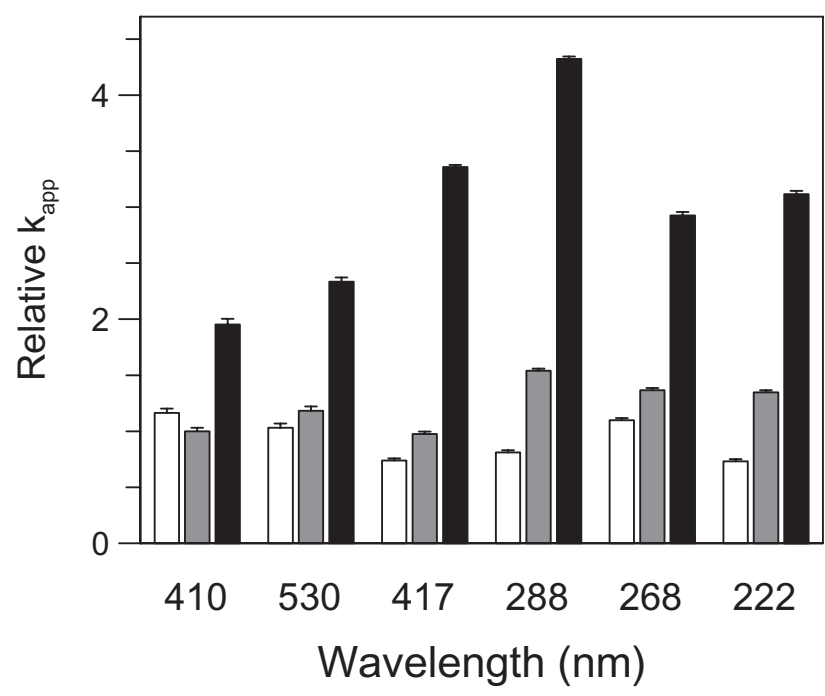

Figure 5. Relative bimolecular rate constant $\left(k_{a p p}\right)$ of the oxidative modification of cyt $c$ followed with absorption spectophotometry at $410 \mathrm{~nm}$ and $530 \mathrm{~nm}$, at $417 \mathrm{~nm}, 288 \mathrm{~nm}, 268 \mathrm{~nm}$ and $222 \mathrm{~nm}$ (measured by CD method) induced by hydrogen peroxide in $10 \mathrm{mmol} \cdot \mathrm{l}^{-1}$ sodium phosphate buffer $\mathrm{pH} 7.0$ in the presence of $1 \mathrm{~mol} \cdot \mathrm{l}^{-1}$ sodium sulfate (white), $1 \mathrm{~mol} \cdot \mathrm{l}^{-1}$ sodium chloride (grey), and $1 \mathrm{~mol} \cdot \mathrm{l}^{-1}$ sodium perchlorate (black). 


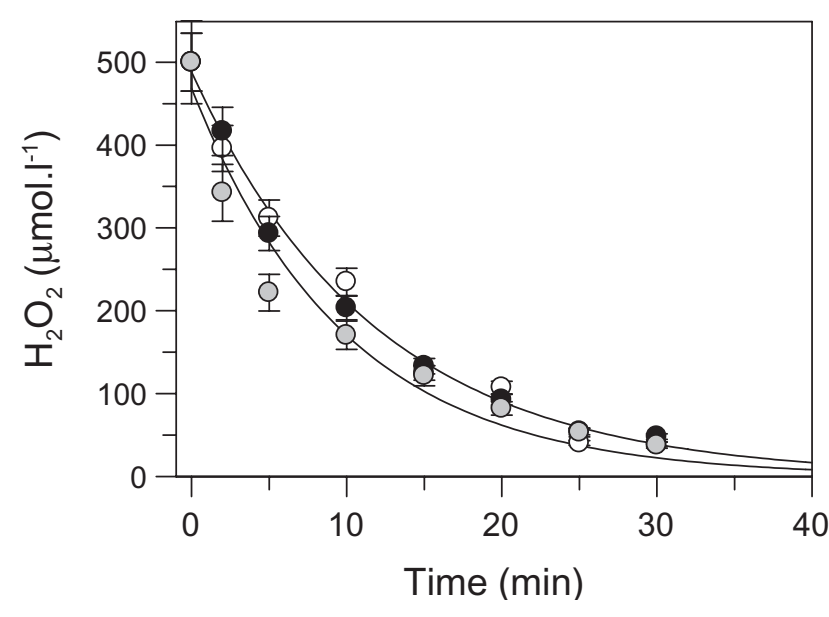

Figure 6. Kinetics of the hydrogen peroxide consumption activity of cyt $c$ in $10 \mathrm{mmol} \cdot \mathrm{l}^{-1}$ sodium phosphate (white circles), in the presence of $1 \mathrm{~mol} \cdot \mathrm{l}^{-1}$ sodium chloride (grey circles), and $1 \mathrm{~mol} \cdot \mathrm{l}^{-1}$ sodium perchlorate (black circles) measured wiht the FOX2 method. The curves show single-exponential fits of the time-dependent decrease of hydrogen peroxide in the presence of chloride and perchlorate sodium salts.

\section{Oxidative modification of cyt c by hydrogen peroxide does not depend on its catalase activity}

A relation between the oxidative modification of cyt $c$ and its catalase activity was also investigated. The catalase activity of cyt $c$ in the presence of salts as well as at low ionic strength was determined by the FOX2 method (Gay et al. 1999; DeLong et al. 2002). However, this method cannot be used for solvents containing $1 \mathrm{~mol} \cdot \mathrm{l}^{-1}$ sodium sulfate due to precipitation of the reagents. Our results show that the catalase activity of cyt $c$ does not depend on the presence and type of salts (Fig. 6). The apparent bimolecular rate constant of the catalase activity of cyt $c$ at pH 6.0 is $\sim 14.01 \cdot \mathrm{mol}^{-1} \cdot \mathrm{s}^{-1}$. The value of the catalase activity of cyt $c$ is in accordance with the reported values (e.g. Radi et al. 1991) and with the reported increase in activity at decreasing $\mathrm{pH}$ (Svistunenko 2005).

\section{Discussion}

Proteins as well as many other cellular components are vulnerable to oxidative stress. Redox-active, heme-containing proteins are frequent suspects as inducers of oxidative stress because of their propensities to produce free radicals and to oxidize important biomacromolecules in peroxidase-like reactions. It has been demonstrated that cyt $c$ shares common features with other heme-containing proteins after interaction with hydrogen peroxide (a reactive oxygen species) (Barr et al. 1996; Villegas et al. 2000; Prasad et al. 2002; Valderrama and Vazquez-Duhalt 2005; Kim et al. 2006).
In the absence of a reductant substrate and in the presence of hydrogen peroxide, cyt $c$ goes through a catalytic pathway containing three active intermediates: Compounds I, II, and III (Arnao et al. 1990). The activated intermediates of cyt $c$ can oxidize amino acids residues in the vicinity of heme group (Prutz 1990; Hawkins and Davies 2001; Kim et al. 2006; Valderrama et al. 2006) as well as cause a cleavage of heme (Valderrama et al. 2002).

Order of oxidative modification of cyt $c$ : heme $\rightarrow$ aromatic amino acids $\rightarrow$ secondary structure

Our experiments show that the rate constants of oxidative modification depend on the localization of the monitored probe in the protein structure (Fig. 5, Table 1). Accessibility and/or sensitivity of the different parts of the heme protein for hydrogen peroxide are dependent on intrinsic properties of protein structure like stability, flexibility, presence and accessibility of sensitive prosthetic groups in its structure. As expected, in the case of cyt $c$ the highest increase in the bimolecular rate constants was observed at the heme region that is partially exposed to solution and is the most sensitive to oxidative reaction. The next group in cyt $c$ that reacts with hydrogen peroxide is aromatic amino acids, likely those localized nearby heme as indicated by changes in CD spectrum of cyt $c$ in the Soret and aromatic regions (Fig. $2 \mathrm{~B}, \mathrm{C})$. Surprisingly, modification of the aromatic amino acids is followed by changes in the far- $U V$ region of $\mathrm{CD}$ spectra of cyt $c$ (Fig. 2A). The decreased content of the secondary structure in cyt $c$ is very likely of a secondary nature, i.e. a result of heme destruction. It is reasonable to expect that the bleaching of the heme will lead to the formation of apoform-like cyt $c$ that is characterized by lower content of the secondary structure (Rankin et al. 1998).

While isosbestic points in the absorption spectrum of cyt $c$ at low concentration of hydrogen peroxide $(\leq 1$ mmol. $\mathrm{l}^{-1}$ ) (Fig. 1, upper row) indicate a one-step transition induced by hydrogen peroxide, an absence of the isosbestic points (Fig. 1, lower row) as well as double-exponential time-dependence at higher concentration of hydrogen peroxide indicate, at least, two parallel processes - oxidative modification and intermolecular covalent interaction between protein molecules (Giulini and Cadenas 1998). Our results provide phenomenological description of the effect of hydrogen peroxide on cyt $c$, and are insufficient to provide detailed description of reaction mechanism of this reaction. In fact, despite an intensive effort the mechanism is not entirely understood.

\section{Role of flexibility for the oxidative modification of cyt $c$}

Recently, we showed that the quenching of tryptophan fluorescence by iodide in NADH oxidase (Žoldák et al. 2004) and 
kinetics of cyanide binding to cyt $c$ is modulated by anions of the Hofmeister series (Varhač et al. 2009). We have suggested that the flexibility/dynamics of a protein plays an important role in the ability of small molecules to penetrate the structure. This is based on the well-known fact that anions of the Hofmeister series affect protein stability (Baldwin 1996; Sedlák et al. 2008) and thus, consequently, flexibility/dynamics of the polypeptide structure (Vihinen 1987; Tang and Dill 1998; Tsai et al. 2001). Moreover, absence of changes in absorption spectrum of cyt $c$ (Varhač et al. 2009) as well as structural studies performed by NMR (Feng and Englander 1990; Moench et al. 1991), X-ray crystallography (Sanishvili et al. 1995), and ultraviolet resonance Raman spectroscopy (Liu et al. 1989) indicate only minor conformational changes in cyt $c$ structure by high ionic strength. However, unspecific (regarding ions) and minor effects of high ionic strength on conformation of cyt $c$ cannot explain observed dependences in fluorescence quenching (Žoldák et al. 2004), kinetics of cyanide binding (Varhač et al. 2009) or our present observations of oxidative modification of cyt $c$ by hydrogen peroxide. On the other hand, our recent work (Varhač et al. 2009) as well as work of Shah and Sweitzer-Stenner (2008) indicates that anions specifically modulate flexibility/dynamics of the heme region of cyt $c$.

Our present results show that the effect of other small molecules (hydrogen peroxide) on cyt $c$ inversely correlates with the stability of its polypeptide chain (Sedlák et al. 2008; Varhač et al. 2009). In fact, the oxidative modification of cyt $c$ in the presence of anions of the Hofmeister series closely correlates with the effect of salts on bimolecular rate constants of binding cyanide to cyt $c$ (Varhač et al. 2009). Surprisingly, the rate of oxidative modification of cyt $c$ in the presence of sulfate anions followed by absorbance spectroscopy at 410 $\mathrm{nm}$ is slightly increased in comparison with the rate in the presence of chloride. This is in accordance with findings indicating unusually increased flexibility of the heme region of cyt $c$ in the presence of kosmotropic anions (Shah and Schweitzer-Stenner 2008; Varhač et al. 2009). Interestingly, the 3.3-fold increase of the bimolecular rate constant of modification of the heme region by hydrogen peroxide in the presence of $1 \mathrm{~mol} \cdot \mathrm{l}^{-1}$ perchlorate anions, compared to conditions without salt, is nearly identical with the increase of the bimolecular rate constant of cyanide binding to cyt $c$ (Varhač et al. 2009).

We would like to point out several structural studies on cyt $c$ that imply a relation between stability of its heme region and its resistance against oxidative modification. It has been shown that replacement of some aromatic (Trp59, Tyr67, Phe82) and aliphatic (Asn52, M80) amino acids cause significantly prolonged half-life of the Soret band (Villegas et al. 2000; Valderrama et al. 2006). While it is generally accepted that aromatic amino acids participate in stabilization of radicals (Miller et al. 1995) or in transfer of primary radicals formed on heme (Lemma-Gray et al. 2007) with deleterious effects both for heme and aromatic amino acids, a protective effect of aliphatic amino acids is not obvious. However, analysis of the location of these mutations indicates that they play role in both local and global stabilities of cyt $c$. In fact, an increased local stability (reflected by shifts of acidic and alkaline transitions to more extreme $\mathrm{pH}$ values), global stability (increase in temperature of thermal transition), and lowered affinity of cyanide for heme iron strongly indicate a decreased flexibility of protein matrix of the mutated cyt $c$ (Luntz et al. 1989; Hickey et al. 1991; Schejter et al. 1992, 1994). This is in accordance with our recent findings that the $\mathrm{p} K_{\mathrm{a}}$ of alkaline isomerization of cyt $c$ closely correlates with its local and global stabilities (Tomášková et al. 2007). Further analysis indicates that this set of mutations partially or completely perturbs interaction of the polypeptide chain with an internal structural water molecule (Wat166) (Berghuis et al. 1994a). The presence of the conservative water molecule in the hydrophobic interior of cyt $c$ has a destabilizing effect on the protein structure (Barrat et al. 2006) with a possible physiological role (Berghuis et al. 1994b). Consequently, its removal leads to an increased stability and lower accessibility of the heme region. These structural studies indirectly support our conclusion regarding a connection between increased flexibility of the heme region and an increased sensitivity to oxidative modification of cyt $c$.

\section{The oxidative modification of cyt $c$ is independent from its catalase activity}

In the presence of Hofmeister anions, the catalase activity of cyt $c$ and its rate constant for oxidative modification are independent. This indicates that the modification is not a deleterious side effect of this activity, but it depends on an inherent property of the protein.

Hemoprotein catalysis with hydrogen peroxide occurs very likely in two distinct phases: i) cleavage of the dioxygen bond to give the catalytic ferryl species, and ii) oxidation of the substrate by electron abstraction or oxygen transfer (Ortiz de Montellano 1987). In the absence of suitable reducing agent, the second step is very slow, as is evident from the low values of bimolecular rate constants. Based on our results, we suggest that the increased flexibility in the presence of perchlorate anions alleviates this rate-limiting step (oxidation of close amino acid residues or the heme). Independence of the second step in the catalase reaction can be explained by fast diffusion of small neutral molecules of hydrogen peroxide through the protein matrix to the heme. This suggestion is in accordance with the conclusion of Lakowicz and Weber quenching experiments, which showed that oxygen diffusion rate through protein matrix is only slightly lower than that in the aqueous solvent (Lakowicz and Weber 1973). 
It should be noted that despite the similar size of hydrogen peroxide and cyanide molecules, binding of the latter to cyt $c$ is significantly slower (Varhač and Antalík 2008; Varhač et al. 2009). This is very likely a consequence of the fact that hydrogen cyanide needs to be deprotonated before interaction with the heme iron. One may also speculate that binding of hydrogen peroxide is governed by bimolecular nucleophilic substitution, $\mathrm{S}_{\mathrm{N} 2}$, mechanism, in contrast with nucleophilic substitution, $\mathrm{S}_{\mathrm{N} 1}$, mechanism of cyanide binding, which would indicate significantly faster binding of hydrogen peroxide to the heme iron.

\section{Conclusions}

The presented results show that the oxidative modifications of cyt $c$ by hydrogen peroxide: i) inversely correlate with the stability of the protein modulated by anions of the Hofmeister series, ii) are independent from its catalase activity. Hydrogen peroxide appears to affect parts of the protein structure dependent on their sensitivity and accessibility (due to an increased flexibility) to the highly oxidative ferryl intermediate. The unusually high stability/rigidity of mesophilic cyt $c$ (as well as other catalases/peroxidases) may be an important feature to prevent deleterious exposure of reactive oxygen species on its structure in its physiological environment.

Acknowledgements. This work was supported by the research grant from the Slovak Grant Agency VEGA No. 1/3252/06 and the P. J. Šafárik University VVGS Grant No. 29/07-08. We thank Gregory Newby for helpful comments and assistance in preparing the manuscript.

\section{References}

Acehan D., Jiang X., Morgan D. G., Heuser J. E., Wang X., Akey C. W. (2002): Three-dimensional structure of the apoptosome: implications for assembly, procaspase-9 binding, and activation. Mol. Cell 9, 423-432; doi:10.1016/S10972765(02)00442-2

Arnao B., Acosta M., del Río J. A., Varón R., García-Cánovas F. (1990): A kinetic study on the suicide inactivation of peroxidase by hydrogen peroxide. Biochim. Biophys. Acta 1041, 43-47

Baldwin R. L. (1996): How Hofmeister ion interactions affect protein stability. Biophys. J. 71, 2056-2063; doi:10.1016/ S0006-3495(96)79404-3

Barr D. P., Gunther M. R., Deterding L. J., Tomer K. B., Mason R. P. (1996): ESR spin-trapping of protein-derived tyrosyl radical from the reaction of cytochrome $\mathrm{c}$ with hydrogen peroxide. J. Biol. Chem. 271, 15498-15503; doi:10.1074/ jbc.271.26.15498

Barratt E., Bronowska A., Vondrásek J., Cerný J., Bingham R., Phillips S., Homans S. W. (2006): Thermodynamic pen- alty arising from burial of a ligand polar group within a hydrophobic pocket of a protein receptor. J. Mol. Biol. 362, 994-1003; doi:10.1016/j.jmb.2006.07.067

Belikova N. A., Vladimirov Y. A., Osipov A. N., Kapralov A. A., Tyurin V. A., Potapovich M. V., Basova L. V., Peterson J., Kurnikov I. V., Kagan V. E. (2006): Peroxidase activity and structural transitions of cytochrome $\mathrm{c}$ bound to cardiolipin-containing membranes. Biochemistry 45, 4998-5009; doi:10.1021/bi0525573

Berghuis A. M., Guillemette J. G., McLendon G., Sherman F., Smith M., Brayer G. D. (1994a): The role of a conserved internal water molecule and its associated hydrogen bond network in cytochrome c. J. Mol. Biol. 236, 786-799; doi:10.1006/ jmbi.1994.1189

Berghuis A. M., Guillemette J. G., Smith M., Brayer G. D. (1994b): Mutation of tyrosine- 67 to phenylalanine in cytochrome c significantly alters the local heme environment. J. Mol. Biol. 235, 1326-1341; doi:10.1006/jmbi.1994.1086

Casella L., De Gioia L., Silvestri G. F., Monzani E., Redaelli C., Roncone R., Santagostini L. (2000): Covalently modified microperoxidases as heme-peptide models for peroxidases. J. Inorg. Biochem. 79, 31-40; doi:10.1016/S01620134(99)00243-3

Dawson J. H. (1988): Probing structure-function relations in hemecontaining oxygenases and peroxidases. Science 240, 433-439; doi:10.1126/science.3358128

DeLong J. M., Prange R. K., Hodges D. M., Forney C. F., Bishop M. C., Quilliam M. (2002): Using a modified ferrous oxidation-xylenol orange (FOX) assay for detection of lipid hydroperoxides in plant tissue. J. Agric. Food Chem. 50, 248-254; doi:10.1021/jf0106695

Deterding L. J., Barr D. P., Mason R. P., Tomer K. B. (1998): Characterization of cytochrome $\mathrm{c}$ free radical reactions with peptides by mass spectrometry. J. Biol. Chem. 273, 12863-12869; doi:10.1074/jbc.273.21.12863

Dukan S., Farewell A., Ballesteros M., Taddei F., Radman M., Nyström T. (2000): Protein oxidation in response to increased transcriptional or translational errors. Proc. Natl. Acad. Sci. U.S.A. 97, 5746-5749; doi:10.1073/pnas.100422497

Feng Y., Englander S. W. (1990): Salt-dependent structure change and ion binding in cytochrome $\mathrm{c}$ studied by two-dimensional proton NMR. Biochemistry 29, 3505-3509; doi:10.1021/bi00466a 012

Gay C., Collins J., Gebicki J. M. (1999): Hydroperoxide assay with the ferric-xylenol orange complex. Anal. Biochem. 273, 149-155; doi:10.1006/abio.1999.4208

Giulivi C., Cadenas E. (1998): Heme protein radicals: formation, fate, and biological consequences. Free Radic. Biol. Med. 24, 269-279; doi:10.1016/S0891-5849(97)00226-8

Hawkins C. L., Davies M. J. (2001): Generation and propagation of radical reactions on proteins. Biochim. Biophys. Acta 1504, 196-219; doi:10.1016/S0005-2728(00)00252-8

Hickey D. R., Berghuis A. M., Lafond G., Jaeger J. A., Cardillo T. S., McLendon D., Das G., Sherman F., Brayer G. D., McLendon G. (1991): Enhanced thermodynamic stabilities of yeast iso-1-cytochromes $c$ with amino acid replacements at positions 52 and 102, J. Biol. Chem. 266, 11686-11694 
Hiner A. N. P., Martinez J. I., Arnao M. B., Acosta M., Turner D. D., Raven E. L., Rodriguez-Lopez J. N. (2001): Detection of a tryptophan radical in the reaction of ascorbate peroxidase with hydrogen peroxide. Eur. J. Biochem. 268, 3091-3098; doi:10.1046/j.1432-1327.2001.02208.x

Kagan V. E., Tyurin V. A., Jiang J., Tyurina Y. Y., Ritov V. B., Amoscato A. A., Osipov A. N., Belikova N. A., Kapralov A. A., Kini V., Vlasova I. I., Zhao Q., Zou M., Di. P., Svistunenko D. A., Kurnikov I. V., Borisenko G. G. (2005): Cytochrome c acts as a cardiolipin oxygenase required for release proapoptotic factors. Nat. Chem. Biol. 1, 223-232; doi:10.1038/nchembio727

Kelly S. M., Jess T. J., Price N. C. (2005): How to study proteins by circular dichroism. Biochim. Biophys. Acta 1751, 119-139

Kelman D. J., DeGray J. A., Mason R. P. (1994): Reaction of myoglobin with hydrogen peroxide forms a peroxyl radical which oxidizes substrates. J. Biol. Chem. 269, 7458-7463

Kim N. H., Jeong M. S., Choi S. Y., Kang J. H. (2006): Oxidative modification of cytochrome $\mathrm{c}$ by hydrogen peroxide. Mol. Cells. 22, 220-227

Lakowicz J. R., Weber G. (1973): Quenching of protein fluorescence by oxygen. Detection of structural fluctuations in proteins on the nanosecond time scale. Biochemistry 12, 4171-4179; doi:10.1021/bi00745a 021

Lawrence A., Jones C. M., Wardman P., Burkitt M. J. (2003): Evidence for the role of a peroxidase compound I-type intermediate in the oxidation of glutathione, $\mathrm{NADH}$, ascorbate, and dichlorofluorescin by cytochrome c/H2O2. Implications for oxidative stress during apoptosis. J. Biol. Chem. 278, 29410-29419; doi:10.1074/jbc.M300054200

Lemma-Gray P., Weintraub S. T., Carroll C. A., Musatov A., Robinson N. C. (2007): Tryptophan 334 oxidation in bovine cytochrome c oxidase subunit I involves free radical migration. FEBS Lett. 581, 437-442; doi:10.1016/j.febslet.2006.12.054

Liu G. Y., Grygon C. A., Spiro T. G. (1989): Ionic strength dependence of cytochrome c structure and Trp-59 H/D exchange from ultraviolet resonance Raman spectroscopy. Biochemistry 28, 5046-5050; doi:10.1021/bi00438a022

Liu X., Kim C. N., Yang J., Jemmerson R., Wang X. (1996): Induction of apoptotic program in cell-free extracts: requirement for dATP and cytochrome c. Cell 86, 147-157

Luntz T. L., Schejter A., Garber E. A., Margoliash E. (1989): Structural significance of an internal water molecule studied by site-directed mutagenesis of tyrosine- 67 in rat cytochrome c. Proc. Natl. Acad. Sci. U.S.A. 86, 3524-3528; doi:10.1073/pnas.86.10.3524

Miller V. P., Goodin D. B., Friedman A. E., Hartmann C., Ortiz de Montellano P. R. (1995): Horseradish peroxidase Phe172-> Tyr mutant. Sequential formation of compound I with a porphyrin radical cation and a protein radical. J. Biol. Chem. 270, 18413-18419

Moench S. J., Shi T. M., Satterlee J. D. (1991): Proton-NMR studies of the effects of ionic strength and $\mathrm{pH}$ on the hyperfineshifted resonances and phenylalanine- 82 environment of three species of mitochondrial ferricytochrome c. Eur. J.
Biochem. 197, 631-641; doi:10.1111/j.1432-1033.1991. tb15953.x

Myer Y. P. (1968): Conformation of cytochromes. 3. Effect of urea, temperature, extrinsic ligands, and $\mathrm{pH}$ variation on the conformation of horse heart ferricytochrome c. Biochemistry 7, 765-776; doi:10.1021/bi00842a035

Ortiz de Montellano P. R. (1987): Control of the catalytic activity of prosthetic heme by the structure of hemoproteins. Acc. Chem. Res. 20, 289-294; doi:10.1021/ar00140a004

Pereverzev M. O., Vygodina T. V., Konstantinov A. A., Skulachev V. P. (2003): Cytochrome c, an ideal antioxidant. Biochem. Soc. Trans. 31, 1312-1315; doi:10.1042/ BST0311312

Pielak G. J., Oikawa K., Mauk A. G., Smith M., Cyril M. K. (1986): Elimination of the negative soret Cotton effect of cytochrome $\mathrm{c}$ by replacement of the invariant phenylalanine using site-directed mutagenesis. J. Am. Chem. Soc. 108, 2724-2727; doi:10.1021/ja00270a035

Pinheiro T. J. (1994): The interaction of horse heart cytochrome c with phospholipid bilayers. Structural and dynamic effects. Biochimie 76, 489-500; doi:10.1016/03009084(94)90173-2

Pinheiro T. J., Cheng H., Seeholzer S. H., Roder H. (2000): Direct evidence for the cooperative unfolding of cytochrome $c$ in lipid membranes from $\mathrm{H}-(2) \mathrm{H}$ exchange kinetics. J. Mol. Biol. 303, 617-626; doi:10.1006/jmbi.2000.4159

Pogni R., Baratto M. C., Giansanti S., Teutloff C., Verdin J., Valderrama B., Lendzian F., Lubitz W., Vazquez-Duhalt R., Basosi R. (2005): Tryptophan-based radical in the catalytic mechanism of versatile peroxidase from Bjerkandera adusta. Biochemistry 44, 4267-4274; doi:10.1021/bi047474l

Prasad S., Maiti N. C., Mazumdar S., Mitra S. (2002): Reaction of hydrogen peroxide and peroxidase activity in carboxymethylated cytochrome c: spectroscopic and kinetic studies. Biochim. Biophys. Acta 1596, 63-75

Prutz W. A. (1990): Free radical transfer involving sulphur peptide functions. In: Sulfur-centered Reactive Intermediates in Chemistry and Biology. (Eds. C. Chatgilialoglu and K. D. Asmus), pp. 389-399, Plenum Press, New York

Radi R., Turrens J. F., Freeman B. A. (1991): Cytochrome c-catalyzed membrane lipid peroxidation by hydrogen peroxide. Arch. Biochem Biophys. 288, 118-125; doi:10.1016/00039861(91)90172-F

Rankin S. E., Watts A., Pinheiro T. J. (1998): Electrostatic and hydrophobic contributions to the folding mechanism of apocytochrome $\mathrm{c}$ driven by the interaction with lipid. Biochemistry 37, 12588-12595; doi:10.1021/bi980408x

Richards F. M. (1992): Protein Folding. (Ed. T. E. Creighton), p. 25, W. H. Freeman and Co., New York

Sanishvili R., Volz K. W., Westbrook E. M., Margoliash E. (1995): The low ionic strength crystal structure of horse cytochrome $\mathrm{c}$ at $2.1 \AA$ resolution and comparison with its high ionic strength counterpart. Structure 3, 707-716; doi:10.1016/S0969-2126(01)00205-2

Schejter A., Luntz T. L., Koshy T. I., Margoliash E. (1992): Relationship between local and global stabilities of proteins: site-directed mutants and chemically-modified deriva- 
tives of cytochrome c. Biochemistry 31, 8336-8343; doi:10.1021/bi00150a030

Schejter A., Koshy T. I., Luntz T. L., Sanishvili R., Vig I., Margoliash E. (1994): Effects of mutating Asn-52 to isoleucine on the haem-linked properties of cytochrome c. Biochem. J. 302, 95-101

Sedlák E., Stagg L., Wittung-Stafshede P. (2008): Effect of Hofmeister ions on protein thermal stability: roles of ion hydration and peptide groups? Arch. Biochem. Biophys. 479, 69-73; doi:10.1016/j.abb.2008.08.013

Shah R., Schweitzer-Stenner R. (2008): Structural changes of horse heart ferricytochrome $\mathrm{c}$ induced by changes of ionic strength and anion binding. Biochemistry 47, 5250-5257; doi:10.1021/bi702492n

Shedbalkar V. P., Modi S., Mitra S. (1988): Preparation and characterisation of iron(IV) porphyrin in aqueous solution at room temperature: a proposed model for peroxidase compound II. J. Chem. Soc. Chem. Commun. 18, 1238-1239; doi:10.1039/c39880001238

Smith M. J., Beck W. S. (1967): Peroxidase activity of hemoglobin and its subunits: effects thereupon of haptoglobin. Biochim. Biophys. Acta 147, 324-333

Strickland E. H. (1974): Aromatic contributions to circular dichroism spectra of proteins. CRC Crit. Rev. Biochem. 2, 113-175; doi:10.3109/10409237409105445

Svistunenko D. A. (2005): Reaction of haem containing proteins and enzymes with hydroperoxides: the radical view. Biochim. Biophys. Acta 1707, 127-155; doi:10.1016/ j.bbabio.2005.01.004

Tang K. E., Dill K. A. (1998): Native protein fluctuations: the conformational-motion temperature and the inverse correlation of protein flexibility with protein stability. J. Biomol. Struct. Dyn. 16, 397-411

Tomášková N., Varhač R., Žoldák G., Olekšáková L., Sedláková D., Sedlák E. (2007): Conformational stability and dynamics of cytochrome $\mathrm{c}$ affect its alkaline isomerization. J. Biol. Inorg. Chem. 12, 257-266; doi:10.1007/s00775-0060183-9

Tsai A. M., Udovic T. J., Neumann D. A. (2001): The inverse relationship between protein dynamics and thermal stability. Biophys. J. 81, 2339-2343; doi:10.1016/S00063495(01) $75880-8$
Valderrama B., Ayala M., Vazquez-Duhalt R. (2002): Suicide inactivation of peroxidases and the challenge of engineering more robust enzymes. Chem. Biol. 9, 555-565; doi:10.1016/S1074-5521(02)00149-7

Valderrama B., Vazquez-Duhalt R. (2005): Electron-balance during the oxidative self-inactivation of cytochrome c. J. Mol. Catalysis B: Enzymatic 35, 41-44; doi:10.1016/j.molcatb.2005.05.003

Valderrama B., Garcia-Arellano H., Giansanti S., Baratto M. C., Pogni R., Vazquez-Duhalt R. (2006): Oxidative stabilization of iso-1-cytochrome $\mathrm{c}$ by redox-inspired protein engineering. FASEB J. 20, 1233-1235; doi:10.1096/fj.054173fje

Varhač R., Antalík M. (2008): Correlation of acid-induced conformational transition of ferricytochrome $\mathrm{c}$ with cyanide binding kinetics. J. Biol. Inorg. Chem. 13, 713-721; doi: 10.1007/s00775-008-0357-8

Varhač R., Tomášková N., Fabián M., Sedlák E. (2009): Kinetics of cyanide binding as a probe of local stability/flexibility of cytochrome c. Biophys. Chem. 144, 21-26; doi:10.1016/ j.bpc.2009.06.001

Vazquez-Duhalt R. (1999): Cytochrome c as a biocatalyst. J. Mol. Catal. B: Enzymatic 7, 241-249; doi:10.1016/S13811177(99)00033-8

Vihinen M. (1987): Relationship of protein flexibility to thermostability. Protein Eng. 1, 477-480; doi:10.1093/protein/1.6.477

Villegas A. J., Mauk A. G., Vazqez-Duhalt R. (2000): A cytochrome c variant resistant to heme degradation by hydrogen peroxide. Chem. Biol. 7, 237-244; doi:10.1016/S10745521(00)00098-3

Zhao Y., Wang Z-B., Xu J-X. (2003): Effect of cytochrome c on the generation and elimination of $\mathrm{O} 2-$ and $\mathrm{H} 2 \mathrm{O} 2$ in mitochondria. J. Biol. Chem. 278, 2356-2360; do$\mathrm{i}: 10.1074 / \mathrm{jbc}$.

Žoldák G., Sprinzl M., Sedlák E. (2004): Modulation of activity of NADH oxidase from Thermus thermophilus through change in flexibility in the enzyme active site induced by Hofmeister series anions. Eur. J. Biochem. 271, 48-57

Received: March 4, 2010

Final version accepted: May 14, 2010 